\title{
Inhibition Effect of Coleus forskohlii leaf extract on Steel Corrosion in 1.0 M HCl Solution: Experimental and Theoretical Approaches
}

\author{
Ismat H. Ali ${ }^{*}$, Riadh Marzouki ${ }^{1,2}$, Youssef Ben Smida ${ }^{3}$,Ameni Brahmia ${ }^{4}$, Mohamed Faouzi Zid ${ }^{2}$ \\ ${ }^{1}$ Department of Chemistry, College of Science, King Khalid University, Abha 61413, Saudi Arabia. \\ ${ }^{2}$ Université de Tunis El Manar, Laboratoire de Matériaux, Cristallochimie et Thermodynamique \\ Appliquée, Faculté des Sciences de Tunis, El Manar II, 2092 Tunis, Tunisia. \\ ${ }^{3}$ National Center of Materials Sciences Research, Technopole Borj Cedria, BP 73, 8027 \\ Soliman,Tunisia. \\ ${ }^{4}$ Materials Chemistry and the Environment Research Unit, University of Tunis El Manar, 2092 Tunis, \\ Tunisia. \\ *E-mail: ismathassanali@gmail.com
}

doi: $10.20964 / 2018.12 .53$

Received: 10 August 2018 / Accepted: 17 Sepember 2018 / Published: 5 November 2018

\begin{abstract}
The inhibitive performance of Coleus forskohlii leaf extract on mild steel corrosion process in $1.0 \mathrm{M}$ $\mathrm{HCl}$ aqueous solutions was studied. Several methods have been adopted such as, mass loss, Tafel polarization curves as well as electrochemical impedance spectroscopy (EIS). The inhibition effectiveness was found to increase as the inhibitor concentration increased. The impact of temperature on corrosion inhibition was studied by using EIS method. The thermodynamic parameters (activation energy, free energy change and entropy change) were calculated. The inhibitor under study is classified as a mixed type inhibitor. Adsorption isotherms models were examined. Adsorption process obeys Langmuir model. The electronic properties concluded from DFT calculations were exploited to give more understandings to the action approach of studied inhibitor. Scanning electron microscope (SEM) and Energy-dispersive X-ray spectroscopy (EDS) were used to explore the efficiency of the inhibitor. The obtained results confirmed the effectiveness of the studied inhibitor.
\end{abstract}

Keywords: mild steel; acid solution; Coleus forskohlii ; inhibition ; corrosion; DFT

\section{FULL TEXT}

(C) 2018 The Authors. Published by ESG (www.electrochemsci.org). This article is an open access article distributed under the terms and conditions of the Creative Commons Attribution license (http://creativecommons.org/licenses/by/4.0/). 